\title{
Characteristics of Enterovesical Fistula Patients Visiting the Urology Department of Dr. Hasan Sadikin General Hospital Bandung, Indonesia, from 2015 to 2019
}

\author{
Daniel Saputra, Tjahjodjati \\ Department of Urology Faculty of Medicine Universitas Padjadjaran \\ Dr. Hasan Sadikin General Hospital Bandung, Indonesia
}

\begin{abstract}
Enterovesical fistula (EVF) represents an abnormal channel between the intestine and the bladder. The EVF is a complication of inflammatory or neoplastic diseases and injuries. Diagnosis of EVF can be challenging and often delayed up to several months after the onset of the symptoms. This study aimed to determine the characteristics of patients with enterovesical fistula visiting Dr. Hasan Sadikin General Hospital Bandung, Indonesia. This retrospective descriptive study used the medical records of EVF patients treated in the urology department of Dr. Hasan Sadikin General Hospital from 2015 to 2019 as the secondary data to be analyzed. A total of 58 patients with EVF were enrolled in this study. By gender, that more than half of the patients were male patients $(n=30,51.7 \%)$ and $45 \%$ of patients were between 41 and 50 years old. The most common symptoms of EVF were pneumaturia and fecaluria which were seen in $30(51.7 \%)$ and 20 (34.5\%) patients, respectively. Twenty-nine (50\%) patients experienced malnutrition and $18(31.1 \%)$ patients had diabetes mellitus as a comorbid. The most common type of fistula was rectovesical fistula $(\mathrm{n}=45,77.6 \%)$ and $26(66.6 \%)$ patients suffered from rectosigmoid cancer and malignancy (68.95) had become the most predominant etiology. Escherichia coli was found in $42(72.4 \%)$ urine cultures collected from the patients and cystoscopy with fistula biopsy was found in $43.1 \%$ of cases, followed by fistula repair $(29.3 \%)$ and urethral catheter drainage (15.5\%). Hence, malignancy and rectosigmoid cancer become the most common etiology of EVF while cystoscopy with fistula biopsy is the most frequently performed procedure.
\end{abstract}

Keywords: Characteristics, enterovesical fistula, urology

\section{Karakteristik Pasien Enterovesical Fistula yang Berkunjung ke Rumah Sakit Dr. Hasan Sadikin Bandung, Indonesia Periode Januari 2015-Desember 2019}

\begin{abstract}
Abstrak
Fistula enterovesikal (EVF) merupakan fistula yang menghubungkan antara usus dan kandung kemih yang dapat terjadi akibat komplikasi dari penyakit inflamasi, neoplastika, dan cedera. Diagnosis EVF sering kali sulit dan tertunda. Walaupun tergolong jarang, penyakit ini menyebabkan morbiditas signifikan dan penurunan kualitas hidup. Penelitian ini bertujuan mengetahui karakteristik pasien EVF di Bagian Urologi RSUP Dr. Hasan Sadikin Bandung periode Januari 2015 sampai Desember 2019. Desain penelitian yang digunakan adalah deskriptif retrospektif. Data dikumpulkan dari rekam medis. Terdapat 58 kasus fistula enterovesikal dalam periode penelitian. Umur tersebar dari 13 sampai 65 tahun, mayoritas pada usia 41 sampai 50 tahun (45\%). Rasio pria lebih tinggi dari wanita. Terdapat 45 kasus (77,6\%) fistula rektovesikal, 11 kasus (19\%) fistula kolovesikal, dan 2 kasus $(3,4 \%)$ fistula ileovesikal. Mayoritas kasus terjadi pada komorbid keganasan $(68,9 \%)$. Gejala tersering adalah pneumaturia $(51,7 \%)$ dan faecaluria (34,5\%). Organisme dominan dalam kultur urin adalah Eschericia coli $(72,4 \%)$. Sebanyak 29 pasien $(50 \%)$ mengalami gizi buruk, 18 pasien $(31,1 \%)$ menderita diabetes melitus dan 11 pasien (18,9\%) tanpa komorbid. Terapi dilakukan dengan sistoskopi biopsi fistula (43,1\%), perbaikan fistula $(29,3 \%)$, dan drainase kateter uretra $(15,5 \%)$. Pneumaturia dan fecaluria merupakan gejala yang paling sering muncul. Keganasan dari kanker rektosigmoid menjadi etiologi yang utama pada EVF. Prosedur sistoskopi dengan biopsi dari fistula adalah prosedur yang paling umum dilakukan.
\end{abstract}

Kata kunci: Fistula enterovesikal, karakteristik, urologi

Corresponding Author: Daniel Saputra, Department of Urology Faculty of Medicine Universitas Padjadjaran/Dr. Hasan Sadikin General Hospital Bandung, Jalan Pasteur No 38 Bandung, Indonesia, Email: danielsaputra.dr@gmail.com 


\section{Introduction}

Enterovesical fistula (EVF) is a condition that represents an abnormal channel between the intestine and the bladder. It is estimated that the incidence of EVF accounts for 1 in every 3,000 surgical hospitals admissions. ${ }^{1,2}$ EVF generally occurs in the sixth and seventh decades of life with a male-to-female ratio of 3:1. The lower incidence in females is due to the interposition of the uterus between the bladder and sigmoid colon. A previous hysterectomy is frequently identified in women with $\mathrm{EVF}^{3}$

EVF is a complication of an inflammatory or neoplastic disease, and traumatic or iatrogenic injuries. Diverticulitis is the most common etiology for this condition, which is identified in $65-79 \%$ of cases, which is almost exclusively colovesical. The relative risk for developing EVF in the presence of diverticular disease is between 1 and $4 \%{ }^{3,4}$ The underlying mechanism is a direct extension of ruptured diverticulum or erosion of a peri-diverticular abscess into the bladder, and phlegmon and abscess are the risk factors for subsequent fistula formation. The second most common cause of EVF is cancer (10-20\% of cases), followed by Crohn's disease (5-7\%). While only approximately $2 \%$ of patients with Crohn's disease develop EVF, ileovesical fistula remains the most common type..$^{1,4}$

The earliest and the most common symptom is urinary tract irritation, which is a recurrent symptom that is difficult to cure. Pathognomonic features of pneumaturia and faecaluria appear later. High compliance of the bladder and low intravesical pressure mean that pneumaturia and fecaluria are more commonly found (50$90 \%)$ than urine flows into the rectum (15\%). Other associated symptoms are fever, dysuria, hematuria, abdominal or pelvic pain, testicular swelling, and leakage of urine from the anus. Gastrointestinal symptoms such as obstruction, constipation, diarrhea, abdominal distention, and abdominal pain that are caused by inflammation are possible. $^{5}$

Diagnosis of EVF can be challenging and is often delayed for several months after the onset of the symptoms. Radiological imaging is crucial for establishing the site, course, and complexity of fistula, and in identifying the etiological factor. ${ }^{6}$ Based on the bowel segment involved, EVF can be divided into four main categories: colovesical (the most common form, usually between the sigmoid colon and bladder dome), rectovesical, ileovesical, and appendicovesical (accounting for less than $5 \%$ of cases)., ${ }^{3,7}$ Although EVF is relatively rare it causes significant morbidity and may markedly affect patient's quality of life. ${ }^{1}$

This study was conducted to determine the characteristics of enterovesical fistula patients at the Urology Department of Dr. Hasan Sadikin General Hospital Bandung, Indonesia, from 2015 to 2019.

\section{Methods}

This was a descriptive study with a retrospective approach. Data were taken from the medical record installation of Dr. Hasan Sadikin General Hospital Bandung. All patients diagnosed with enterovesical fistula treated at the Department of Urology of Dr. Hasan Sadikin General Hospital from January 1, 2015 to December 31, 2019 were included.

The inclusion criterion used was all patients with enterovesical fistula diagnosis who were admitted to the Urology Department of Dr. Hasan Sadikin General Hospital Bandung during the period of January 12015 to December 312019. Data recorded were age, gender, enterovesical fistula types, etiology, symptoms, microorganism in urine culture, patient's comorbidity, and enterovesical fistula management. Meanwhile, patients were excluded when the medical record was incomplete. All data were then presented in descriptive tables and graphs.

This study had been approved by the Health Research Ethics Committee of Dr. Hasan Sadikin General Hospital Bandung under the ethical clearance number LB.02.01/X.6.5/65/2021

\section{Results}

As shown in Table 1, during the period January 2015 to December 2019, there were 58 cases of enterovesical fistula that were treated at the Urology Department. The age of these patients ranged from 13 to 65 years old, with most were between 41 and 50 years old $(n=9,45 \%)$.

Of the 58 patients with enterovesical fistula, $30(51.7 \%)$ were males and 28 (48.3\%) were females. Time wise, there were 10 patients $(17.2 \%)$ in $2015,8(13.8 \%)$ in 2016,9 (15.52\%) in $2017,19(32.8 \%)$ in 2018, and 12 (20.7\%) in 2019.

From the 58 identified cases of enterovesical fistula, it was found that 45 cases $(77.6 \%)$ were rectovesical fistula cases, 11 cases (19\%) were colovesical fistula, and two cases (3.4\%) were ileovesical fistula. Dysuria and recurrent 
D Saputra and Tjahjodjati: Characteristics of Enterovesical Fistula Patients Visiting the Urology Department of Dr. Hasan Sadikin General Hospital Bandung, Indonesia

Table 1 Patients Characteristics

\begin{tabular}{lcc}
\hline \multicolumn{1}{c}{ Characteristics } & n & (\%) \\
\hline Gender & 30 & 51.7 \\
$\quad$ Male & 28 & 48.3 \\
$\quad$ Female & & \\
Distribution of year & 10 & 17.2 \\
2015 & 8 & 13.8 \\
2016 & 9 & 15.5 \\
2017 & 19 & 32.8 \\
2018 & 12 & 20.7 \\
2019 & & \\
Symptoms & 30 & 51.7 \\
$\quad$ Pneumaturia & 20 & 34.5 \\
Fecaluria & 6 & 10.4 \\
Abdominal pain & 2 & 3.4 \\
$\quad$ Urine leakage from rectum & & \\
Comorbidity & 29 & 50 \\
$\quad$ Malnutrition & 18 & 31.1 \\
$\quad$ Diabetes mellitus & 11 & 18.9 \\
$\quad$ No comorbidity & & \\
Type of enterovesical fistula & 45 & 77.6 \\
$\quad$ Rectovesical & 11 & 19 \\
Colovesical & 2 & 3.4 \\
Ileovesical & & \\
\hline
\end{tabular}

urinary tract infections were observed in all patients. Other common symptoms of EVF were pneumaturia and fecaluria in 51.7\% (30) and $34.5 \%$ (20) of patients, respectively. Abdominal pain as the leading symptom of EVF was observed in six patients $(10.4 \%)$ in this study. In addition, two patients with rectovesical fistula (3.4\%) presented with urinary leakage from the rectum.

From perspective of the comorbidity factor, 29 patients (50\%) were experiencing malnutrition, 18 patients (31.1\%) were suffering from diabetes mellitus, and 11 patients (18.9\%) were without

Table 2 Type of Malignancy and Microorganism Culture Pattern

\begin{tabular}{lcc}
\hline \multicolumn{1}{c}{ Type of Malignancy } & n & (\%) \\
\hline Cervical cancer & 4 & 10.3 \\
Colorectal cancer (Descendens) & 6 & 15.4 \\
Bladder cancer & 3 & 7.7 \\
Rectosigmoid cancer & 26 & 66.6 \\
Microorganism & & \\
Eschericia coli & 42 & 72.4 \\
Klebsiella sp. & 10 & 17.3 \\
Enterococcus spp. & 5 & 8.6 \\
\hline
\end{tabular}

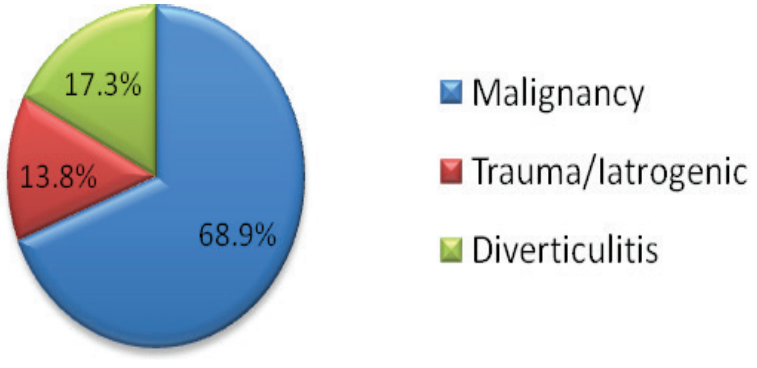

Figure 1 Patients Distribution Based on Etiology

any comorbidity.

The etiologies of the enterovesical fistula as shown in Figure 1 were trauma or iatrogenic, malignancy, and diverticulitis, with malignancy as the most frequent cause of the enterovesical fistula (68.9\%). These malignancies were divided into cervical cancer $10.3 \%$ (4 patients), colon descended cancer $15.4 \%$ ( 6 patients), bladder cancer $7.7 \%$ (3 patients), and rectosigmoid cancer $66.6 \%$ (26 patients).

In urine cultures collected from enterovesical fistula patients, Eschericia coli was found in 42 patients (72.4\%) while Klebsiella sp and Enterococcus spp. were found in 10 (17.3\%), and $5(8.6 \%)$ patients, respectively. One patient $(1.7 \%)$ did not reveal any microorganism.

Based on the enterovesical fistula patients, all patient management, these patients were given antibiotics, and symptomatic drugs. There were 9 patients $(15.5 \%)$ treated by urethral catheter drainage, 25 (43.1\%) treated by fistula biopsy, 17 (29.3\%) underwent fistula repair and 7 (12.1\%) did not receive any intervention (Figure 2).

\section{Discussion}

The first description of EVF was made by Rufus of Ephesus in AD 200, whilst in the modern

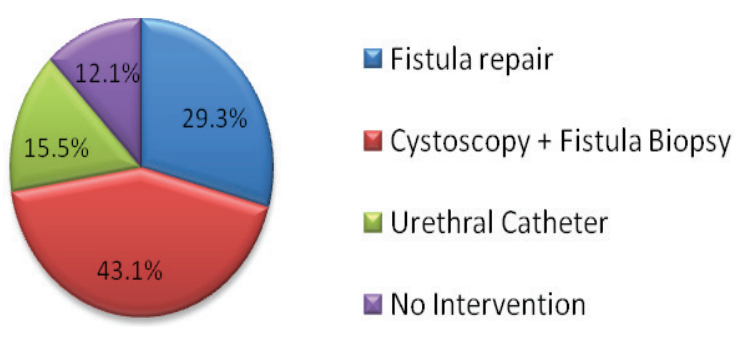

Figure 2 Patients Distribution Based on Management 
literature, Cripps was the first to report the condition in 1888. EVF occurs mainly in the sixth and seventh decades of life. It is quite different from our study which states that the distribution of age is from 13 to 65 years old, the patients are mostly between 41 and 50 years old due to several factors such as life expectancy, The ratio between males and females is also different, but the male ratio is higher than females. Based on literature, the sex ratio of male-to-female was $3: 1$; lower incidence in females is due to the interposition of the uterus between the bladder and sigmoid colon and a previous hysterectomy is frequent in women with EVF.1,2,3

EVF most frequently occurs in inflammatory bowel diseases. Diverticulitis is the most common etiology, accounting for approximately 65-79\% of cases, which are almost exclusively colovesical. The second most common cause of EVF is cancer $(10-20 \%$ of cases), which is followed by Crohn's disease (5-7\%). While only approximately $2 \%$ of patients with Crohn's disease develop EVF, ileovesical fistula remains the most common type of EVF. The iatrogenic etiology of enterovesical fistula may occur as a consequence of general surgical procedures, particularly for colorectal cancer, vascular, and urological interventions. ${ }^{1,8,9}$ In this study, the most common etiology of EVF was malignancy, followed by diverticle and iatrogenic etiology. Colorectal cancer is the most common malignancy reported in this study, which is similar to a study by Ferguson. ${ }^{11}$ From the 58 cases of enterovesical fistula analyzed, 45 cases $(77.6 \%)$ were rectovesical fistula, 11 cases $(19 \%)$ were colovesical fistula, and 2 cases (3.4\%) were ileovesical fistula. Malignancy was found to be the most frequently found setting for EVF in this study (68.9\%).

Enterovesical fistula symptoms may originate from both urinary and gastrointestinal tracts. However, patients with EVF usually present with lower urinary tract symptoms, which include pneumaturia as the most common symptom (50- 70\%), fecaluria (up to $51 \%$ ), frequency, urgency, suprapubic pain, recurrent urinary tract infections (UTIs), and hematuria. Similarities of symptoms were seen between patients in our study and those in previous studies. Over $75 \%$ of the affected patients describe pathognomonic features of pneumaturia, fecaluria, and recurrent UTIs caused by Escherichia coli, coliformbacteria, mixed growth, or enterococcus. The physical signs include malodorous urine and debris in the urine, as well as less commonly reported fever. Additionally, symptoms of underlying diseases causing the fistula may be observed, such as abdominal pain, abdominal mass, and abscess. ${ }^{1}$ ${ }^{7,10}$ In this study, dysuria and recurrent urinary tract infections were found in all patients. Other common symptoms of EVF were pneumaturia and faecaluria, which were noted in $51.7 \%$ (30) and 34.5\% (20) of patients, respectively. The abdominal pain as the leading symptom of EVF was reported in 6 patients $(10.4 \%)$ while two patients with rectovesical fistula (3.4\%) presented with urinary leakage from the rectum. Urine culture usually shows mixed fecal flora, with the predominant organism being Eschericia coli $(72.4 \%)$, followed by Klebsiella sp. (17.3\%), and Enterococcus spp. (8.6\%).

In this study, the enterovesical fistula was accompanied by comorbidity factors, including malnutrition, as seen in $50 \%$ of the patients, and diabetes mellitus (31.1\%). Meanwhile $18.9 \%$ of patients did not have any comorbidity. Several factors have also led to an increase in the number of fistula, particularly in high risk patients, such as old age, malnourished condition, or metabolic diseases. Patients' comorbidity can also increase the mortality and morbidity rates. ${ }^{8}$

Non-operative treatments of EVF may be an option in nontoxic, minimally symptomatic patients with non-malignant origin. Nonsurgical management of colovesical fistula is generally reserved for those patients that are not suitable candidates for major interventions or with extensive unresectable neoplastic processes. For these cases, medical therapy with catheter drainage of the bladder alone or supravesical percutaneous diversion could be beneficial. Cystoscopy evaluation should be performed in all patients with genitourinary symptoms. ${ }^{1,7}$

The operative management of enterovesical fistula is mainly dependent on the underlying pathology, site of the bowel lesion, and patient's pre-operative status. The operative management aims to resect and anastomose the offending bowel segment and to close the bladder. Before the main surgery, a fistula biopsy should be done for histopathologic and diagnostic examinations. The treatment may involve single-stage or multistage procedures. The former procedure involves resection and primary anastomosis without a protective colostomy, while the latter involves resection and primary anastomosis with colostomy and/or Hartmann procedure (two-stage procedure) with later closure of the stoma (three-stage approach). ${ }^{1,8}$ In this study, all patients were given antibiotics and symptomatic drugs. There were 9 patients $(15.5 \%)$ that were treated by urethral catheter drainage, 25 patients (43.1\%) underwent fistula biopsy, 17 
patients $(29.3 \%)$ underwent fistula repair, and the rest were not treated $(12.1 \%)$.

The limitation of this study stems from the fact that there are incomplete medical records or medical records with missing data; thus, not all cases treated at the Urology Department of Dr. Hasan Sadikin General Hospital Bandung were included in this study.

Male is the predominant gender in this study with a peak incidence in the $4^{\text {th }}$ to $5^{\text {th }}$ decade. Malnutrition is the most common comorbid in these patients, with pneumaturia and fecaluria as the most significant symptoms. Malignancy and rectosigmoid cancer becomes the most common etiology of EVF, with rectovesical fistula as the most common type. Furthermore, $E$. Coli has been identified as the most common urinary microorganism culture in our patients and cyystoscopy with fistula biopsy is the most frequently performed procedure in our hospital.

\section{References}

1. Golabek T, Szymanska A, Szopinski T, Bukowczan J, Furmanek M, Powroznik J, et al. Enterovesical fistulae: aetiology, imaging, and management. Gastroenterol Res Pract. 2013;2013:617967.

2. Shaydakov ME, Pastorino A, Tuma F. Enterovesical Fistula. [Updated 2021 Sep 14]. In: StatPearls [Internet]. Treasure Island (FL): StatPearls Publishing; 2021 Jan. Available from: https://www.ncbi.nlm.nih. gov/books/NBK532936/

3. Holroyd D, Banerjee S, Beavan M, Prentice R, Vijay V, Warren SJTic. Colovaginal and colovesical fistulae: the diagnostic paradigm. 2012;16(2):119-26.

4. Ye X, Liu Y, He Q. Enterovesical fistula in an Elderly Crohn's Disease Patient. Clin Gastroenterol Hepatol. 2019;17(11):e129.

5. Li S, Chen Z, Zhang Q, Huang C, Wang Z, Du S. Four cases of enterovesical fistula and the importance of CT in the diagnosis. BJR Case Rep. 2016;3(1):20150124.

6. Dziki L, Wlodarczyk M, SobolewskaWlodarczyk A, Mik M, Trzcinski R, Hill AG, et al. Is suturing of the bladder defect in benign Enterovesical fistula necessary?. BMC Sur. 2019;19(1):85.

7. Kaimakliotis P, Simillis C, Harbord M, Kontovounisios C, Rasheed S, Tekkis PP. A Systematic review assessing medical treatment for rectovaginal and enterovesical fistulae in Crohn's Disease. J Clin Gastroenterol. 2016;50(9):714-21

8. Benlice C, Nishtala M, Steele SR. Management of enterovesical fistula. Mastery of IBD Surgery: Springer; 2019. p. 219-26.

9. Lee YT, Chen YY, Wu CY, Chen HM, Tzeng CH. Enterovesical fistula caused by regressive change of non-Hodgkin's lymphoma: A case report. Oncol Lett. 2016;12(1):331-3.

10. Giovanni C, Emanuele C, Roberto C, Alberto P, Emanuele L, Alessia C, et al. Laparoscopic conservative surgery of colovesical fistula: is it the right way?. Wideochir Inne Tech Maloinwazyjne. 2013;8(2):162-5.

11. Ferguson GG, Lee EW, Hunt SR, Ridley $\mathrm{CH}$, Brandes SB. Management of the bladder during surgical treatment of enterovesical fistulas from benign bowel disease. J Am Coll Surg. 2008;207(4):569-72. 